\title{
Interleukin-6 Functions as an Intracellular Growth Factor in Hairy Cell Leukemia In Vitro
}

\author{
Bruce Barut, Dharminder Chauhan, Hiroshi Uchiyama, and Kenneth C. Anderson \\ Division of Tumor Immunology, Dana-Farber Cancer Institute and the Department of Medicine, \\ Harvard Medical School, Boston, Massachusetts 02115
}

\begin{abstract}
The role of interleukin-6 (IL-6) in the growth of B cell derived hairy cell leukemia (HCL) was characterized. Purified hairy cells (HCs) did not increase DNA synthesis in vitro in response to exogenous IL-6; however, they expressed IL-6 receptor (IL6R) mRNA and bound directly fluorochrome labeled IL-6. IL6 mRNA was not detectable in tumor cells by Northern blotting, but was evident using PCR amplification. Although intracytoplasmic IL-6 protein was not demonstrable, HCs did secrete low levels of IL-6. Neutralizing antibody to IL-6 did not inhibit HC DNA synthesis. Since tumor necrosis factor (TNF) is a growth factor for HCL, we determined whether the TNF effect could be IL-6-mediated. TNF markedly augmented in vitro DNA synthesis by HCs. TNF did not alter IL-6R expression or IL-6 binding; however, IL-6 mRNA and IL-6 protein were detectable after 3-d culture of HCs with TNF. In addition, IL-6 secretion by HCs was markedly augmented by TNF. Finally, although neither IL-6 nor anti-IL-6 antibody altered TNF-induced DNA synthesis by HCs, IL-6 antisense oligonucleotide inhibited TNF-induced DNA synthesis and IL-6 secretion by HCs. Therefore, IL-6 does not directly affect the growth of HCL, but rather mediates TNF-induced DNA synthesis via an intracytoplasmic mechanism. (J. Clin. Invest. 1993. 92:2346-2352.) Key words: B cell malignancy • tumor necrosis factor $\bullet$ interleukin -6 antisense oligonucleotide $\bullet$ IL 6 receptors - autocrine growth factor
\end{abstract}

\section{Introduction}

Hairy cell leukemia (HCL) ${ }^{1}$ is now generally accepted to be of $B$ cell origin on the basis of phenotypic and gene rearrangement profiles. Previous work in our laboratory has demonstrated that HCL may correspond to late stage B (pre-plasma) cells on the basis of their phenotype and functional repertoire (1). Moreover, multiple studies have demonstrated responsiveness of hairy cells (HCs) to growth factors for normal human B cells

Address correspondence to Dr. Kenneth C. Anderson, Division of Tumor Immunology, Dana-Farber Cancer Institute, and the Department of Medicine, Harvard Medical School, 44 Binney Street, Boston, MA 02115.

Received for publication 14 September 1992 and in revised form 5 April 1993.

1. Abbreviations used in this paper: 2-cda, 2-chlorodeoxyadenosine; $\mathrm{HC}$, hairy cell; HCL, hairy cell leukemia; $\left[{ }^{3} \mathrm{H}\right] \mathrm{TdR},\left[{ }^{3} \mathrm{H}\right]$ thymidine; TRAP, tartrate-resistant acid phosphatase.

J. Clin. Invest.

(c) The American Society for Clinical Investigation, Inc.

$0021-9738 / 93 / 11 / 2346 / 07 \quad \$ 2.00$

Volume 92, November 1993, 2346-2352
(2-8). HCs can be stimulated to proliferate in vitro with B cell growth factor (BCGF), which has been proposed as an autocrine growth factor in this disease $(3,5)$. Tumor necrosis factor (TNF) has also been reported to be an autocrine growth factor in HCL, since in vitro culture with TNF induces HCs to proliferate and to generate both TNF mRNA and protein (6). Finally, the combination of interleukin-4 (IL-4) and IL-5 also induces in vitro DNA synthesis by $\mathrm{HCs}$, although neither factor alone affects HC growth $(7,8)$. Although these lymphokines have demonstrated in vitro effects, their role in the pathophysiology of HCL is not yet delineated.

Interleukin- 6 triggers the terminal differentitation of normal B cells and has been shown to induce the growth of murine plasmacytomas and hybridomas and Epstein Barr Virus-transformed human B lymphocytes (9-12). It has also been proposed to be either an autocrine or paracrine growth factor in human chronic lymphocytic and acute myelocytic leukemia, non-Hodgkin's lymphoma and multiple myeloma cells (13$20)$. In vitro evidence exists for both autocrine and paracrine mechanisms of IL-6 stimulation of myeloma cell line growth (21-24). Moreover, high serum IL-6 levels observed in patients with advanced myeloma and plasma cell leukemia, coupled with transient inhibition of myeloma cell growth using anti-IL-6 antibodies in vivo, suggest a role for IL- 6 in the pathophysiology of myeloma $(25,26)$. Previous studies in HCL suggest that tumor cells do not respond to $\operatorname{IL}-6$ in vitro $(7,8)$. Although both IL- 6 mRNA and IL- 6 protein have both been reported in $\mathrm{HCs}(7,27)$, its role in regulation of HCL growth is not precisely defined.

In the present report, the role of IL-6 in the regulation of HCL growth was characterized. Purified tumor cells expressed functional cell surface IL-6 receptors (IL-6Rs), were IL-6 mRNA positive by PCR, and secreted low levels of IL-6 in vitro; however, neither exogenous IL-6 nor neutralizing antibody to IL-6 altered in vitro DNA synthesis by tumor cells. TNF markedly augmented DNA synthesis of HCs in vitro, which was specifically blocked by IL-6 antisense oligonucleotide and not by IL- 6 sense oligonucleotide or neutralizing antiIL- $6 \mathrm{mAb}$. These data suggest that IL-6 does not play a direct role in the growth of HCL, but rather plays an indirect role by mediating TNF-induced DNA synthesis via an intracytoplasm mechanism.

\section{Methods}

Preparation of HCL populations. Splenic samples were obtained from four patients with HCL. The diagnosis of HCL was made on the basis of clinical presentation, as well as histopathologic (Wright-Giemsa) and histochemical (tartrate-resistant acid phosphatase, TRAP) features. Patient samples were immediately placed in medium containing $5 \%$ FBS, minced, extruded through stainless steel mesh, and cryopreserved until use. Ficoll-Hypaque mononuclear cell preparations were enriched for tumor cells by E-rosette depletion of $\mathrm{T}$ cells and removal of monocytes by adherence to plastic Petri dishes $\left(1 \mathrm{~h}, 37^{\circ} \mathrm{C}\right)$. 
Characterization of HCL populations. HC-enriched populations were characterized morphologically, histochemically, and phenotypically. Morphology was examined by Wright-Giemsa staining, and HCL-associated histochemistry was defined by TRAP staining (28). The populations of enriched leukemia cells were also examined using mAbs directed at B, T, and myeloid antigens ( Ags) in indirect immunofluorescence assays as previously described (7). Monoclonal reagents used to characterize the HCs included the following: anti-B4(CD19), B1 (CD20), B2(CD21), interleukin-2R(IL-2R; CD25), and PCA-1, which are reactive with $B$ cells at various stages of differentiation; antiT3(CD3), T4(CD4), and T8(CD8), which identify T cells; antiMol(CD1lb) and Mo2(CD14), which stain monocytoid cells; and anti-IL-6 receptor (MT-18), kindly provided by T. Taga (29-37).

Culture of HCs with growth factors, IL-6 antisense, sense, and missense oligonucleotides, anti-IL-6 antibody and 2-chlorodeoxyadenosine. Recombinant IL-6 was generously provided by Dr. Steven Clark (Genetics Institute, Cambridge, MA). TNF was a gift from Dr. Donald Kufe (Dana-Farber Cancer Institute, Boston, MA). These factors were used at concentrations of maximal activity in standard assays based upon previous work (7). A 15 base antisense oligonucleotide, specific for a sequence in exon II of the IL- 6 gene previously described as effective in reducing growth in Kaposi sarcoma cells (38), a control sense oligonucleotide and a control missense oligonucleotide of the same base compostion were synthesized by cyanoethyl phosphoramidite methodology. The oligonucleotides were purified by Sephadex column and ethanol precipitation and resuspended in sterile water. The oligonucleotides were used at a concentration of $15 \mu \mathrm{M}$. A murine neutralizing mAb against IL- 6 was provided by Dr. Edward Alderman (Genetics Institute) and used at a concentration (1:100), which blocks $100 \mathrm{U} / \mathrm{ml}$ of IL-6 in standard assays. The compound 2-chlorodeoxyadenosine (2-cda) was provided by Dr. David Gordon (R. W. Johnson Pharmaceutical Research Institute, Raritan, NJ) and used at concentrations reported previously to have in vitro cytotoxicity for HCL (39).

$100-\mu \mathrm{l}$ aliquots containing $5 \times 10^{4}$ purified HCs in RPMI/10\% FBS medium were dispensed into 96-well round-bottomed tissue culture plates (Costar, Cambridge, MA). The serum had been heated to $66^{\circ} \mathrm{C}$ for $45 \mathrm{~min}$ to reduce the exonuclease activity and thus increase the half-life of oligodeoxynucleotides. Cells were cultured in the presence of media or growth factors at appropriate concentrations to a final culture volume of $200 \mu \mathrm{l} /$ well. All studies were done in triplicate. In vitro DNA synthesis by HCs in response to growth factors was measured at days $1,3,5,7$ and 9 of culture using $\left[{ }^{3} \mathrm{H}\right]$ thymidine $\left({ }^{3}[\mathrm{H}] \mathrm{TdR}\right)$ uptake. Cells were pulsed with ${ }^{3}[\mathrm{H}] \mathrm{TdR}$ during the last 16 $h$ of incubation $(0.2 \mu \mathrm{Ci} /$ well $)$, harvested onto glass filters with the aid of an automated cell harvester (Cambridge Technology, Cambridge, MA), and counted on a liquid scintillation counter (Packard Tri-Carb 4530, Downers Grove, IL). Significant proliferation was defined as a stimulation index $\left(\mathrm{SI},{ }^{3}[\mathrm{H}] \mathrm{TdR}\right.$ uptake of sample $/{ }^{3}[\mathrm{H}] \mathrm{TdR}$ uptake of control) $\geq 3.0$. The anti-IL-6 mAb, IL-6 sense, antisense, and missense oligonucleotides and 2-cda were added at the initiation of culture. The oligonucleotides were replenished daily for experiments lasting for $3 \mathrm{~d}$ or every other day for experiments extending to $9 \mathrm{~d}$. Cells were harvested at intervals of maximal DNA synthesis.

$I L-6$ receptor binding assay. IL-6 directly labeled with phycoerythrin (IL-6PE) was obtained from R + D Systems (Minneapolis, $M N)$. HCs were washed and incubated with IL-6PE according to manufacturer's directions. Labeled cells were enumerated by flow cytometric analysis using an Epics $\mathrm{C}$ cell sorter (Coulter Electronics, Hialeah, FL). Cell samples were incubated with excess unlabeled IL-6 $(1,000 \mathrm{U} / \mathrm{ml})$ to demonstrate specificity of IL-6PE binding. The U266 myeloma cell line, known to strongly express IL-6R (24), and the CEM T acute lymphoblastic leukemia cell line served as positive and negative controls, respectively.

Northern blot analysis. Total cellcular RNA was isolated from HCs by the method of Chomczynski and Sacchi (40). Polyadenylated RNA was isolated by the use of oligo ( $\mathrm{dT}$ ) cellulose methodology (Invitrogen Corp., San Diego, CA). RNA samples were fractionated on $1.0 \%$ agarose gel with $6 \%$ formaldehyde and transferred onto a nylon membrane filter (Magnagraph; Micron Separations Inc. [MSI], Westboro, MA). The blots were prehybridized according to manufacturer's recommendations.

Hybridization was performed using probes for IL-6 and IL-6R. A full-length IL- 6 cDNA was provided by Dr. S. Clark (Genetics Institute). A Ban II-Taq 1 fragment (nucleotides 215-657) was labeled by random oligonucleotide priming using alpha ${ }^{32} \mathrm{P}$-labeled deoxyribonucleotide and Klenow fragment of DNA polymerase I. Hybridization took place at $42^{\circ} \mathrm{C}$ in the presence of $2 \times \mathrm{SSC}, 50 \%$ formamide, $5 \times$ Denhardt's, and $100 \mu \mathrm{g} / \mathrm{ml}$ denatured salmon sperm DNA. Filters were rinsed in decreasing concentrations of SSC and SDS at $50^{\circ} \mathrm{C}$ to a final stringency of $0.1 \times \mathrm{SSC}$ for $15 \mathrm{~min}$ and exposed to X-AR5 $\mathrm{x}$-ray film (Kodak, Rochester, NY) at $-70^{\circ} \mathrm{C}$ using intensifying screens. T24, a human urothelial tumor cell line known to secrete IL-6, served as a positive control for IL- 6 mRNA. Polyadenylated RNA from the HCs was probed for IL-6R mRNA using a Pst-Xho I fragment (nucleotides 578-1764) of IL-6R cDNA (gift from T. Taga) (41). Filters were rehybridized with human glyceraldehyde 3-phosphate dehydrogenase to confirm equivalent loading of RNA.

$P C R$ analysis. cDNA was synthesized from $1 \mu \mathrm{g}$ samples of total RNA from the T24 cell line and from HCs using M-MLV reverse transcriptase $(200 \mathrm{U} / \mu \mathrm{l})(\mathrm{BRL}$, Gaithersburg, MD). The reverse transcriptase reaction product was used for subsequent PCR amplification of specific cDNA through the use of oligodeoxynucleotide primers spanning 639 base pairs of IL- 6 mRNA ( 24 bp; nucleotide sequences 34 through 672). The specific PCR reaction parameters were as follows: 30 cycles of $1 \mathrm{~min}$ at $94^{\circ} \mathrm{C}, 1 \mathrm{~min}$ at $60^{\circ} \mathrm{C}, 3 \mathrm{~min}$ at $72^{\circ} \mathrm{C}$ followed by a 7 -min extension at $72^{\circ} \mathrm{C}$. The PCR reaction mixture contained ${ }^{32} \mathrm{P}$-labeled dCTP $(4 \mu \mathrm{Ci} / \mathrm{ml})$ The PCR product was electrophoresed in $5.0 \%$ acrylamide gel, and the PCR fragments were analyzed by autoradiography using exposure to X-AR5 $\mathrm{x}$-ray film.

Measurement of IL-6 bioactivity. IL- 6 levels in the supernatants obtained from 3-d or 7-d cultures of HCs were measured in a bioassay by using IL- 6 dependent B9 cells as previously described (42). Test samples were heat-inactivated and sterile filtered before use. Varying dilutions of the test samples or IL-6 were added to wells containing 5 $\times 10^{3} \mathrm{~B} 9$ cells for $72 \mathrm{~h}$, with the addition of ${ }^{3}[\mathrm{H}] \mathrm{TdR}$ for the last $4 \mathrm{~h}$ of culture. Thymidine uptake by the B9 cells was determined as described above.

Western blot analysis. The presence of the IL- 6 protein in in HCs was assayed through the use of immunoblotting utilizing a murine anti-IL-6 mAb. Equal aliquots of cells were lysed in 1\% NP-40 and the detergent solubilized protein was electrophoresed through a $17.5 \%$ SDS polyacrylamide gel (PAGE). Protein was transferred to nitrocellulose (Nitroplus 2000; MSI) in a Hoefer mini-Transphor unit for $14 \mathrm{~h}$ at 75 $\mathrm{mA}$. The nitrocellulose filters were then preincubated in PBS containing $2 \%$ BSA. The filters were incubated with anti-IL-6 mAb at a concentration of 1:1,000 for $1 \mathrm{~h}$, washed extensively, and then incubated with a second antibody (peroxidase-conjugated goat anti-mouse IgG). The blots were further washed and developed with 3,3"-diaminobenzidine tetrahydrochloride.

\section{Results}

Morphologic, histochemical, and phenotypic characterization of HCL populations. Ficoll-Hypaque mononuclear cells were obtained from the spleens of four patients with HCL. T cells and monocytes were depleted by E-rosetting followed by adherence to plastic. The E-rosette negative nonadherent cell population demonstrated the morphological features of HCs by Wright-Giemsa staining and was TRAP positive. The cell surface phenotype is displayed in Table I. The B cell restricted (pan-B cell) Ags B1 and B4 were strongly expressed on a majority (75-93\%) of cells; in contrast, only a minority of cells (24$46 \%$ ) bore cell surface B2 Ag. The IL-2R, Mo1, and the plasma cell associated PCA-1 Ags were present on $46 \%$ to $74 \%, 65 \%$ to 
Table I. Cell Surface Phenotype of Hairy Cell-enriched Populations

\begin{tabular}{cccccccc}
\hline & \multicolumn{7}{c}{ Percentage of cells bearing antigen* } \\
\cline { 2 - 8 } Patient & B1 & B2 & B4 & Mo1 & PCA-1 & IL-2R & IL-6R \\
\hline 1 & 89 & 27 & 91 & 83 & 83 & 74 & 77 \\
2 & 78 & 46 & 84 & 87 & 80 & 46 & 78 \\
3 & 93 & 38 & 92 & 81 & 75 & 56 & 76 \\
4 & 75 & 24 & 78 & 65 & 78 & 50 & 70 \\
\hline
\end{tabular}

* Mononuclear cells were isolated from spleens of patients with HCL by Ficoll-Hypaque density sedimentation. E-rosetting and adherence were used to remove $T$ cells and macrophages, respectively. The resulting hairy cell enriched populations were examined using indirect immunofluorescence and flow cytometric analysis.

$87 \%$ and $75 \%$ to $83 \%$ cells, respectively. The MT- $18 \mathrm{mAb}$, directed against IL-6R, was reactive with $70 \%$ to $78 \%$ of cells. T cell restricted (T3, T4, T8) and monocyte restricted (Mo2) Ags were minimally expressed $(<5 \%)$ on $\mathrm{HCL}$ enriched populations.

Response and mechanisms of response of HCs to growth factors. The HCL populations were cultured with TNF, IL-6, IL-6 sense, missense or antisense oligonucleotides, anti-IL-6 $\mathrm{mAb}$, and 2-cda, either singularly or in combination, and assayed for DNA synthesis after various days of culture. Spontaneous ${ }^{3}[\mathrm{H}] \mathrm{TdR}$ uptake by the HCs cultured in media alone was minimal $(<1,200 \mathrm{cpm})$ (Table II). TNF markedly increased (4-10-fold) DNA synthesis at day 3 (patients 1 and 2) or day 7 (patients 3 and 4), whereas DNA synthesis in the presence of IL-6, IL-6 sense, missense or antisense oligonucleotides, anti-IL-6 mAb, or 2-cda was not significantly different from cultures with media alone. No significant additive or inhibitory effects were seen when IL-6 or anti-IL-6 mAb was cultured with TNF. IL- 6 antisense, but not IL- 6 sense or mis- sense oligonucleotides, significantly decreased DNA synthesis induced by TNF. 2-cda demonstrated effects similar to IL-6 antisense oligonucleotide.

After $3 \mathrm{~d}$ of culture of HCs (patient 2) with media, TNF, TNF + IL-6 sense oligonucleotide, TNF + IL-6 antisense oligonucleotide, TNF + IL-6 missense oligonucleotide, or TNF $+2 \mathrm{cda}$, the percentage of viable cells was $65 \%, 84 \%, 79 \%, 84 \%$, $77 \%$, and $24 \%$, respectively, confirming that the oligonucleotides were not toxic to tumor cells.

$I L-6$ receptor binding assay. HCs were evaluated for specific binding of IL-6PE to assay for presence of functional IL6Rs. Flow cytometric analysis demonstrated specific IL-6PE binding of $76 \%$ on the U266 cell line, known to be IL- 6 responsive (Fig. $1 A$ ); in contrast, no binding of IL-6 PE was observed on the $\mathrm{T}$ acute lymphoblastic leukemia cell line CEM, which is nonresponsive to IL-6 (Fig. $1 \mathrm{~B}$ ). $80-85 \%$ strong binding of IL-6 PE to HCs from four patients was noted (Fig. $1 C$ and $D$ ). This was specific, as evidenced by complete blocking of IL-6 PE binding to HCs preincubated with an excess of unlabeled IL-6. No significant changes in IL-6 binding were noted in HCs cultured with TNF for $3 \mathrm{~d}$ (Fig. $1 E$ ).

Expression of IL-6 and IL-6 receptor $m R N A$ transcripts in HCs. The expression of IL-6 mRNA in total RNA isolated from HCs was examined by Northern blot analysis. The $1.3 \mathrm{~kb}$ transcript for IL-6 mRNA was present in the T24 bladder cell line (Fig. $2 A$, lane 1 ) but was absent in the CEM cell line (lane 2) and freshly isolated HCs (lanes 3 and 4). In contrast, IL-6 mRNA was demonstrated after $3 \mathrm{~d}$ of culture with TNF (Fig. 3 $A$, lanes 5 and 6 ). With increased sensitivity using PCR amplification, IL-6 mRNA was again observed in T24 (Fig. 2 B, lane 1) and lacking in CEM cells (lane 2). It was readily detectable in freshly isolated HCs both before (lanes 3 and 4 ) and after $3 \mathrm{~d}$ of culture with TNF (lanes 5 and 6 ).

Expression of IL-6R mRNA, as evidenced by a single $5.3 \mathrm{~kb}$ band on Northern blot analysis of polyadenylated RNA, was present in the RPMI 8226 myeloma cell line (Fig. 3, lane 1)

Table II. Response of Hairy Cells to Recombinant Growth Factors ${ }^{3}[H] T d R$ Uptake (Stimulation Index)*

\begin{tabular}{lcccc}
\hline \multicolumn{1}{c}{ Stimulus+ } & Patient 1 & Patient 2 & Patient 3 & Patient 4 \\
\hline Media & $1175 \pm 234$ & $401 \pm 241$ & $296 \pm 28$ & $339 \pm 201$ \\
TNF & $9887 \pm 998(8.4)$ & $3822 \pm 627(9.5)$ & $1327 \pm 260(4.5)$ & $3453 \pm 177(10.2)$ \\
IL-6 & $1114 \pm 326(0.9)$ & $336 \pm 209(0.8)$ & $405 \pm 224(1.4)$ & $206 \pm 84(0.6)$ \\
anti-IL-6 mAb & $2095 \pm 181(1.8)$ & $384 \pm 77(1.0)$ & $247 \pm 32(0.8)$ & $200 \pm 67(0.6)$ \\
IL-6 sense oligonucleotide & $1172 \pm 498(1.0)$ & $312 \pm 172(0.8)$ & $392 \pm 195(1.3)$ & $184 \pm 71(0.5)$ \\
IL-6 antisense oligonucleotide & $758 \pm 143(0.6)$ & $314 \pm 217(0.8)$ & $307 \pm 82(1.0)$ & $260 \pm 75(0.8)$ \\
IL-6 missense oligonucleotide & $1021 \pm 103(0.9)$ & $481 \pm 128(1.2)$ & $504 \pm 167(1.7)$ & $242 \pm 61(0.7)$ \\
2-cda & $413 \pm 241(0.4)$ & $294 \pm 53(0.7)$ & $207 \pm 63(0.7)$ & $281 \pm 17(0.8)$ \\
TNF + IL-6 & $9717 \pm 253(8.3)$ & $3900 \pm 914(9.7)$ & $949 \pm 192(3.2)$ & $3282 \pm 740(9.7)$ \\
TNF + anti-IL-6 mAb & $9392 \pm 113(8.0)$ & $4863 \pm 252(12.1)$ & $1064 \pm 97(3.6)$ & $3503 \pm 663(10.3)$ \\
TNF + IL-6 sense & $9236 \pm 614(7.9)$ & $2713 \pm 443(6.8)$ & $1159 \pm 355(3.9)$ & $2077 \pm 1152(6.1)$ \\
TNF + IL-6 antisense & $1692 \pm 634(1.4)$ & $810 \pm 170(2.0)$ & $480 \pm 75(1.6)$ & $1249 \pm 168(3.7)$ \\
TNF + IL-6 missense & $8827 \pm 1130(7.5)$ & $3796 \pm 1007(9.5)$ & $1004 \pm 392(3.4)$ & $2675 \pm 955(7.9)$ \\
TNF + 2-cda & $444 \pm 144(0.4)$ & $300 \pm 83(0.8)$ & $228 \pm 53(0.8)$ & $453 \pm 375(1.3)$
\end{tabular}

* 100- $\mu$ l aliquots containing $5 \times 10^{4}$ purified HCLs in RPMI/10\% FBS medium were dispensed into 96-well round-bottomed tissue culture plates. Cells were cultured in the presence of media or growth factors at appropriate concentrations to a final culture volume of $200 \mu \mathrm{l} / \mathrm{well}$. Experiments were performed in triplicate. Cells were pulsed with $0.2 \mu \mathrm{Ci} /$ well $\left[{ }^{3} \mathrm{H}\right] \mathrm{TdR}$ after $56 \mathrm{~h}$ (patients 1 and 2 ) or $152 \mathrm{~h}$ (patients 3 and 4 ) in culture and were harvested onto glass filters and counted on a scintillation counter (mean $\pm \mathrm{SEM}$ ) $16 \mathrm{~h}$ later. Stimulation index $=\left[{ }^{3} \mathrm{H}\right] \mathrm{TdR}$ uptake of sample/ $/[\mathrm{H}] \mathrm{TdR}$ uptake of control. 


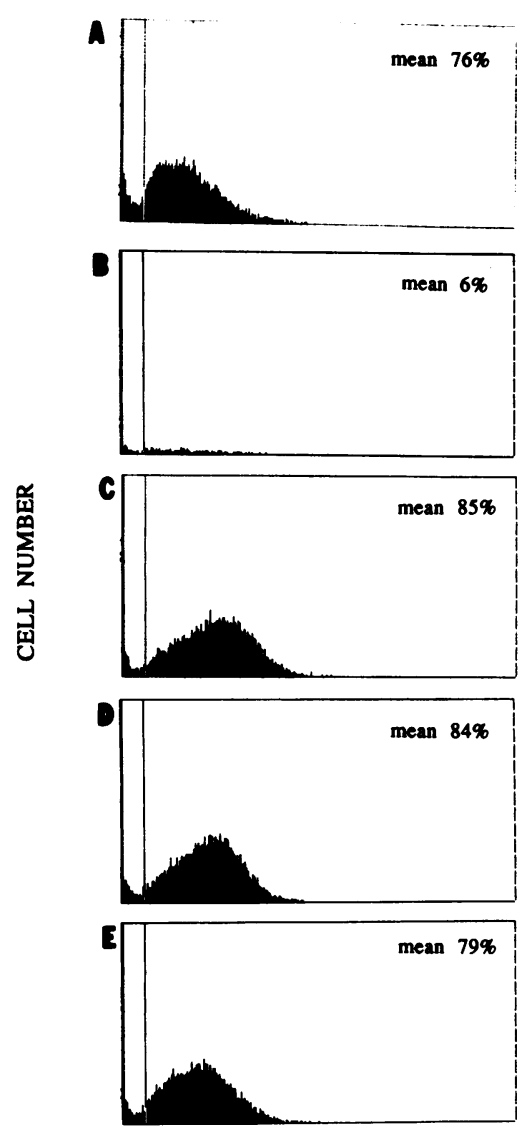

LOG FLUORESCENCE INTENSTTY
Figure 1. Binding of IL6 to HCs. HCs were incubated with IL- 6 directly conjugated to phycoerythrin. Labeled cells were enumerated by flow cytometric analysis. The $\mathrm{U} 266(A)$ and $\operatorname{CEM}(B)$ cell lines served as positive and negative controls, respectively. Two representative HCL patients' samples are seen in $C$ and $D$ (patients 3 and 2 , respectively). (E) Demonstrates the IL-6 expression on HCs (patient 2) cultured for 3 d with TNF.

and absent in CEM cells (lane 2). Tumor cells freshly isolated from patients with HCL also expressed IL-6R mRNA (lanes 3 and 4).

Secretion of IL-6 by HCs. HCs were cultured with media, TNF, and TNF plus either IL-6 sense, missense or antisense oligonucleotides for 3 or $7 \mathrm{~d}$. Supernatants from these cultures were added to B9 cells to test for IL-6 bioactivity. Incubation of the B9 cells with oligonucleotides alone did not result in significant changes in thymidine incorporation by the cells. As can be seen in Fig. 4 , low levels $(5 \pm 0.9 \mathrm{U} / \mathrm{ml}$ ) of IL- 6 were secreted by HCs cultured in media alone. Culture with TNF reproducibly increased IL-6 secretion by HCs threefold $(16.1 \pm 2.4 \mathrm{U} / \mathrm{ml})$. B9 cells were not stimulated when cultured with TNF alone. Culture with IL-6 antisense oligonucleotide inhibited (> 90\%) TNF-induced IL-6 secretion by HCs $(1.4 \pm 0.4 \mathrm{U} / \mathrm{ml}$ IL-6). In contrast, IL- 6 secretion in the presence of TNF and IL- 6 sense oligonucleotide $(12.7 \pm 4.5 \mathrm{U} / \mathrm{ml})$ was not significantly different from that triggered by TNF. IL- 6 missense oligonucleotide also did not alter IL-6 secretion induced by TNF (data not shown).

Expression of intracytoplasmic IL-6 protein. The presence of IL- 6 protein within the cytoplasm of HCs was examined using immunoblotting. The IL-6 protein of approximately 75 $\mathrm{kD}$ was demonstrable in the cytoplasm of $\mathrm{T} 24$ cells (positive control; Fig. 5, lane 1) and absent in CEM cells (negative control, lane 2). Although this protein was not present in freshly isolated HCL tumor samples (lanes 3 and 4 ) or in HCs cultured for $3 \mathrm{~d}$ in media alone (data not shown), it was readily detectable after 3-d culture with TNF (lanes 5 and 6 ).

\section{$\begin{array}{llllll}1 & 2 & 3 & 4 & 5 & 6\end{array}$}

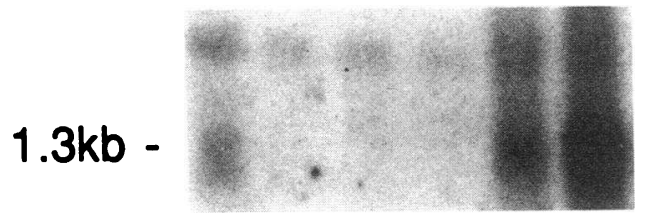

B

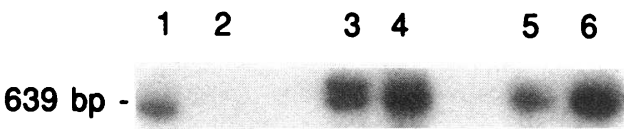

Figure 2. (A) Expression of IL-6 mRNA in HCs detected by Northern blot analysis. $15 \mu \mathrm{g}$ of total RNA was isolated from HCs before and after culture with TNF for $3 \mathrm{~d}$. The RNA was fractionated on agarose gels, transferred to nylon membrane and hybridized with a ${ }^{32} \mathrm{P}$-labeled IL-6 cDNA probe. The T24 (lane 1) and CEM (lane 2) cell lines served as positive and negative controls, respectively. RNA isolated from 2 patients' (lanes 1 and 2) HCs lacked IL-6 mRNA (lanes 3 and 4). After incubation for $3 \mathrm{~d}$ with TNF, HCs (patients 1 and 2) expressed the $1.3 \mathrm{~kb} \mathrm{IL-6} \mathrm{mRNA}$ (lanes 5 and 6 ). ( $B$ ) Expression of IL- 6 mRNA in HCs as detected by PCR. Total RNA ( $1 \mu \mathrm{g})$ from 2 HCL patients (lanes 2 and 3 ) was reverse transcribed and PCR with oligonucleotides specific for IL-6 used to amplify the cDNA product. RNA from the T24 (lane 1) and CEM (lane 2) cell lines served as positive and negative controls, respectively. HCs before (lanes 3 and 4 ) and after 3-d culture with TNF (lanes 5 and 6 ) expressed IL-6 mRNA.

\section{Discussion}

In this report, we have characterized the role of IL-6 in the growth of HCL. Enrichment for tumor cells was confirmed by characteristic phenotypic and histochemical staining. HCs expressed IL-6R mRNA and functional IL-6R, but did not increase DNA synthesis in response to exogenous IL-6. IL-6 mRNA was detectable in tumor cells by PCR and these cells secreted low levels of IL-6, but neutralizing anti-IL-6 mAb did not inhibit their growth. TNF markedly upregulated DNA synthesis in HCs, with concomitant increments in IL-6 mRNA and IL- 6 secretion. Most importantly, IL- 6 antisense oligonu-
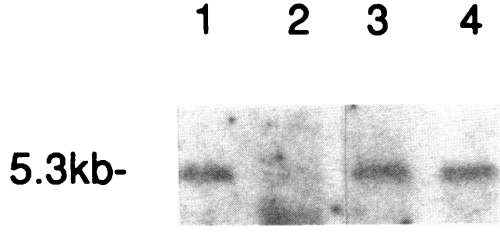
ized with a ${ }^{32} \mathrm{P}$-labeled IL-6R cDNA probe. The $5.3 \mathrm{~kb}$ IL-6R mRNA was present in RPMI 8226 cells (lane 1 ), as well as HCs from 2 patients (lanes 3 and 4 , patients 2 and 4 , respectively). The CEM cell line served as a negative control (lane 2 ). 


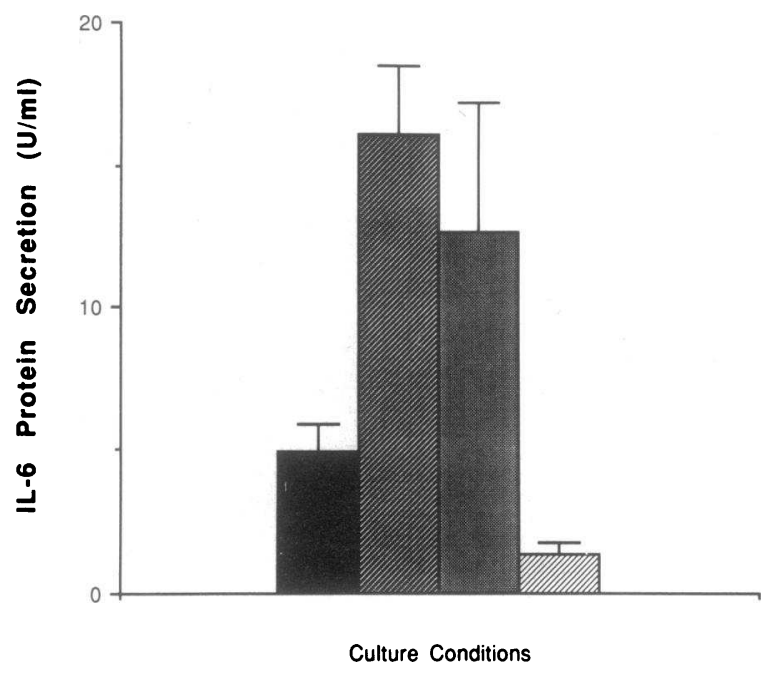

Figure 4. Secretion of IL-6 by HCs. HCs were cultured for 3 or $7 \mathrm{~d}$ with: media ( $\square)$; TNF ( $\square$ ); TNF + IL-6 sense oligonucleotide ( $\square$ ); or TNF + IL-6 antisense oligonucleotide (ש). Supernatant from the cultures were harvested, heat inactivated, filter sterilized, and added to B9 cells to test for IL- 6 bioactivity. Values represent the mean plus standard deviation of duplicate experiments in two representative patients (lanes 1 and 2).

cleotide specifically inhibited both DNA synthesis and IL-6 secretion triggered by TNF. These data suggest that IL- 6 mediates the effects of TNF on HCL growth via an intracytoplasmic mechanism.

Previous studies have suggested that $\mathrm{HCL}$ is of B cell origin and may represent a pre-plasma cell malignancy (1). Since IL-6 triggers terminal differentiation of normal B cells and has been proposed as either an autocrine or paracrine growth factor for myeloma (16-20), it was of interest to characterize its role in HCL growth. In this and other $(7,8)$ studies, IL-6 did not augment in vitro DNA synthesis in HCs. Also, anti-IL-6 did not inhibit spontaneous growth of HCs in vitro. Therefore IL-6 did not serve as an autocrine growth factor. Both TNF and

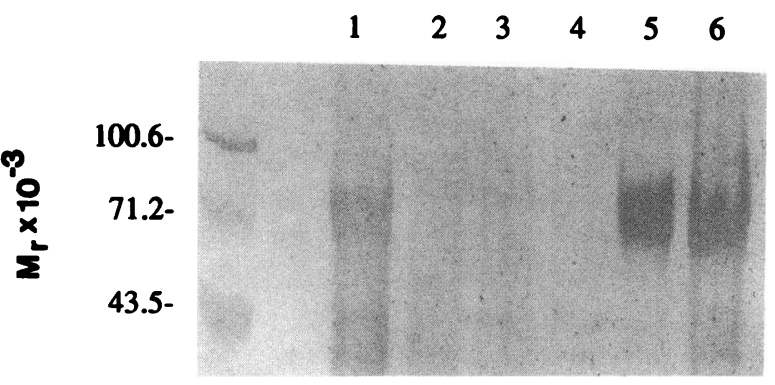

Figure 5. Western blot analysis for intracytoplasmic IL-6 protein in HCs. Cells were lysed in 1\% NP-40 and SDS-PAGE was performed using $17.5 \%$ gels. Protein was transferred to nitrocellulose filters and incubated with a murine anti-IL-6 mAb. Filters were then washed extensively and incubated with peroxidase-conjugated anti-mouse IgG. Blots were further washed and developed with 3,3"-diaminobenzidine tetrahydrochloride. T24 (lane 1) and CEM (lane 2) cells served as positive and negative controls, respectively. HCs from 2 patients ( 1 and 2 ) (lanes 3 and 4 ) lacked detectable IL-6 protein. After 3 days of culture with TNF, the IL-6 protein of $\sim 75 \mathrm{kD}$ was demonstrable (patients 1 and 2 in lanes 5 and 6 , respectively).
BCGF have previously been reported to be autostimulatory growth factors in $\operatorname{HCL}(3,5,6)$; moreover, increased serum levels of TNF have been noted in patients with HCL, suggesting that it may play a role in HCL growth in vivo $(43,44)$. Our results confirm that TNF augments DNA synthesis by purified HCs in vitro. In addition, the blocking of this response by IL-6 antisense oligonucleotide, but not by anti-IL-6 neutralizing $\mathrm{mAb}$, suggests that it is mediated by IL-6 in an intracytoplasmic mechanism. This is analogous to previous reports of autocrine systems wherein cell growth is insensitive to exogenous growth factors and neutralizing antibodies are unable to inhibit proliferation (45-49). Such systems are compatible with a mechanism whereby receptor association and signal transduction both occur internally. This intriguing paradox in regulation in which a growth factor lacks activity when binding to an external receptor but appears functional in an internal mechanism (i.e., when binding to the identical receptor within the cytoplasm) warrants further study.

The interplay of IL- 6 and TNF has also been noted in other systems. Brach et al., for example, reported that TNF enhanced IL-6 mRNA transcripts in monocytes (50). These authors further demonstrated that both TNF and lymphotoxin bound to the same receptor, but the former enhanced steady state levels of IL-6 mRNA transcripts in monocytes due to mRNA stabilization, whereas the latter shortened IL-6 mRNA half-life. This observation may have relevance in HCL since TNF- $\alpha$, but not lymphotoxin, stimulates cell growth (51). In B cells, activation triggers TNF earlier than IL-6, but both are required for Ig secretion (52). Moreover, anti-TNF antibody partially blocks IL-6 production and Ig secretion by normal B cells. Finally, increased levels of IL-6 mRNA transcripts have been demonstrated in acute myeloblastic leukemia blasts and polymorphonuclear neutrophils, respectively, after stimulation with $\operatorname{TNF}(53,54)$. Thus, TNF induces IL- 6 production in a variety of normal and malignant cells.

Interferon- $\alpha$ and 2-cda have demonstrated efficacy in the treatment of HCL (55), but their exact mechanism of action is unknown. Interferon- $\alpha$ has been shown to inhibit in vitro DNA synthesis induced in HCs by various growth factors $(4,7$, $8,56)$. It induces ultrastructural alterations in HCs, supporting the notion that it impairs $\mathrm{HC}$ responsiveness to $\mathrm{B}$ cell growth factors by altering the target cells (56). In B chronic lymphocytic leukemia and HCL, IFN- $\alpha$ shortens the half-life of TNF mRNA (27). These studies suggest that IFN- $\alpha$ may interrupt a TNF autocrine growth mechanism in HCL. However, other studies present conflicting or alternative mechanisms of IFN's effects; i.e., it may act in HCL by affecting CD20 phosphorylation (57), or by inducing differentiation (58). Moreover, some studies directly contradict the notion that IFN- $\alpha$ interrupts a TNF autocrine growth mechanism in HCL and suggest that IFN- $\alpha$ both enhances the expression of cell surface TNF and IL-6 receptors and augments TNF production by HCs (5961). The cytotoxic effect of 2-cda in HCL is proposed to result from the accumulation of its 5'-triphosphate form in cells with high deoxycytidine kinase activity, resulting in DNA strand breaks and ATP depletion (55). The present data suggest that future studies should examine whether either IFN- $\alpha$ or 2-cda may also be acting via their effects on IL-6 mediated growth of HCL.

The mechanism whereby TNF induces IL-6 in HCL is undefined. There are several potential transcriptional control elements, such as glucocorticoid-responsive elements, an AP-1 
binding site, a c-fos serum- responsive element homology, a cyclic AMP-responsive element, and an NF- $\mathrm{B}$ binding site within the IL-6 promoter (62). Previous studies suggest that the induction of IL- 6 by TNF appears to involve an IL- 6 promoter element termed inflammatory lymphokine-responsive element (ILRE; 63). The ILRE sequence is highly homologous to NF- $\kappa$ B transcription factor binding motifs and binds an IL1-TNF- $\alpha$ inducible nuclear factor. The sequence specificities, binding characteristics, and subcellular localizations of this factor are indistinguishable from those of $\mathrm{NF}_{\kappa} \mathrm{B}$. In addition, mutations of the ILRE sequence that impair the binding of this nuclear factor abolish the induction of IL- 6 gene expression by IL-1 and TNF- $\alpha$ in vivo $(64,65)$ Thus, a nuclear factor indistinguishable from NF- $\kappa$ B is involved in the transcriptional activation of the IL- 6 gene by IL- 1 and TNF- $\alpha(66)$. Future experiments using appropriate IL-6 promoter constructs in CAT reporter assays will determine whether the effects of TNF- $\alpha$ on IL-6 induction in HCs similarly involve activation of the ILRE sequence within the IL-6 promoter.

\section{Acknowledgments}

The authors are grateful to Mr. Herbert Levine for technical assistance in flow cytometry. We also thank Ms. Bernadette Miner for secretarial assistance during the preparation of this manuscript.

The work was supported by the National Institutes of Health grant CA50947.

\section{References}

1. Anderson, K. C., A. W. Boyd, D.C. Fisher, D. Leslie, S. F. Schlossman, and L. M. Nadler. 1985. Hairy cell leukemia: A tumor of pre-plasma cells. Blood. 65:620-629.

2. Ghaderi, A. A., P. Richardson, C. Cardona, M. J. Millsum, N. Ling, S. Gillis, J. Ledbetter, and J. Jordan. 1988. Stimulation of B-chronic lymphocytic leukemia populations by recombinant interleukin- 4 and other defined growthpromoting agents. Leukemia. 2:165-170.

3. Ford, R. J., D. Kwok, J. Quesada, and C. G. Sahasrabuddhe. 1986. Production of B cell growth factor(s) by neoplastic B cells from hairy cell leukemia patients. Blood. 67:573-577.

4. Paganelli, K. A., S. S. Evans, T. Han, and H. Ozer. 1986. B cell growth factor-induced proliferation of hairy cell lymphocytes and inhibition by type I interferon in vitro. Blood. 67:937-942.

5. Ford, R. J., L. Yoshimura, J. Morgan, J. Quesada, R. Montagna, and A. Maizel. 1985. Growth factor-mediated tumor cell proliferation in hairy cell leukemia. J. Exp. Med. 162:1093-1098.

6. Cordingley, F. T., A. V. Hoffbrand, H. E. Heslop, M. Turner, A. Bianchi, J. E. Reittie, A. Vyakarnam, A. Meager, M. K. Brenner. 1988. Tumor necrosis factor as an autocrine tumor growth factor for chronic B-cell malignancies. Lancet. 1:969-971.

7. Barut, B. A., M. K. Cochran, C. O'Hara, and K. C. Anderson. 1990. Response patterns of hairy cell leukemia to B-cell mitogens and growth factors. Blood. 76:2091-2097.

8. Griffiths, S. D., and J. C. Cawley. 1990. The effect of cytokines, including IL-1, IL-4, and IL-6, in hairy cell proliferation/differentiation. Leukemia. 4:337340 .

9. Hirano, T., K. Yasukawa, H. Harada, T. Taga, Y. Watanbe, T. Matsuda, S. Kashiwamura, K. Nakajima, K. Koyama, A. Iwamatu, et al. 1986. Complementary DNA for a novel human interleukin (BSF-2) that induces B lymphocytes to produce immunoglobulin. Nature (Lond.). 324:73-76.

10. Tanner, J. E., and G. Tosato. 1992. Regulation of B-cell growth and immunoglobulin gene transcription by interleukin-6. Blood. 79:452-459.

11. Tosato, G., J. Tanner, K. Jones, M. Revel, and S. Pike. 1990. Identification of interleukin-6 as an autocrine growth factor for Epstein-Barr virus-immortalized B cells. J. Virol. 64:3033-3041.

12. Van Damme, J. G., Opdenakker, R. J. Simpson, M. R. Rubira, S. Cayphas, A. Vink, A. Billiau, and J. van Snick. 1987. Identification of the human $26-\mathrm{kD}$ protein, interferon $\beta 2$ (IFN- $\beta 2$ ), as a B cell hybridoma/plasmacytoma growth factor induced by interleukin 1 and tumor necrosis factor. J. Exp. Med. 165:914-919.

13. Yee, C., A. Biondi, X. H. Wang, N. N. Iscove, J. Sousa, L. A. Aarden,
G. G. Wong, S. C. Clark, H. A. Messner, and M. D. Minden. 1990. A possible autocrine role for interleukin-6 in 2 lymphoma cell lines. Blood. 74:798-804.

14. Biondi, A., V. Rossi, R. Bassan, T. Barbui, S. Bettoni, M. Sironi, A. Mantovani, and A. Rambaldi. 1989. Constitutive expression of the interleukin 6 gene in chronic lymphocytic leukemia. Blood. 73:1279-1284.

15. Oster, W., N. A. Cicco, H. Klein, T. Hirano, T. Kishimoto, R. Mertelsmann, and F. Herrmann. 1989. Participation of the cytokines IL-6, TNF-alpha, and IL-1 beta secreted by acute myelogenous leukemia blasts in autocrine and paracrine leukemia growth control. J. Clin. Invest. 84:451-457.

16. Kawano, M., T. Hirano, T. Matsuda, T. Taga, Y. Horii, K. Iwato, H. Asaoku, B. Tang, O. Tanabe, H. Tanaka, A. Kuramoto, and T. Kishimoto. 1988. Autocrine generation and requirement of BSF-2/IL-6 for human multiple myelomas. Nature (Lond.). 332:83-85.

17. Klein, B., X. Zhang, M. Jourdan, J. Content, F. Houssiau, L. Aarden, M. Piechaczyk, and R. Bataille. 1989. Paracrine rather than autocrine regulation of myeloma-cell growth and differentiation by interleukin-6. Blood. 73:517-526.

18. Zhang, X. G., B. Klein, and R. Bataille. 1989. Interleukin-6 is a potent myeloma-cell growth factor in patients with aggressive multiple myeloma. Blood. 74:11-13.

19. Caligaris-Cappio, F., L. Bergui, M. Gregoretti, G. Gaidano, M. Bagoli, M. Schena, A. Zollane, and P. Marchisio. 1991. Role of bone marrow stromal cells in the growth of human multiple myeloma. Blood. 77:2688-2693.

20. Anderson, K. C., R. C. Jones, C. Morimoto, P. Leavitt, and B. Barut. 1989. Response of purified myeloma cells to hematopoietic growth factors. Blood. 73:1915-1924.

21. Jackson, N., J. Lowe, J. Ball, E. Bromidge, N. R. Ling, S. Larkins, M. J. Griffith, and I. M. Franklin. 1989. Two new IgA $A_{1}$ - plasma cell leukemia cell lines (JJN1 \& JJN2) which proliferate in response to B cell stimulatory factor 2. Clin. Exp. Immunol. 75:93-99.

22. Shimizu, S., R. Yoshioka, Y. Hirose, S. Sugai, J. Tachibana, and S. Konda. 1989. Establishment of two interleukin-6 (B-cell stimulatory factor $2 /$ in terferon- $\beta 2$ ) dependent human bone marrow derived myeloma cell lines. J. Exp. Med. 169:339-344.

23. Hitzler, J., H. Martinez-Valdez, D. Bergsagel, M. Minden, and H. Messner. 1991. Role of interleukin-6 in the proliferation of human multiple myeloma cell lines OCI-MY 1 to 7 establish from patients with advanced stage of the disease. Blood. 78:1996-2004.

24. Barut, B. A., L. I. Zon, M. K. Cochran, S. R. Paul, D. Chauhan, A. Mohrbacher, J. Fingeroth, and K. Anderson. Role of interleukin-6 in the growth of myeloma derived cell lines. Leukemia Res. 16:951-959.

25. Bataille, R., M. Jourdan, X. G. Zhang, and B. Klein. 1989. Serum levels of interleukin-6, a potent myeloma cell growth factor, as a reflection of disease severity in plasma cell dyscrasias. J. Clin. Invest. 84:2008-2011.

26. Klein, B., J. Wijdenes, X. G. Zhang, M. Jourdan, J. M. Boiron, J. Brochier, J. Liautard, M. Merlin, C. Clement, B. Morel-Fournier, et al. Murine anti-interleukin-6 monclonal antibody therapy for a patient with plasma cell leukemia. Blood. 78:1198-1204.

27. Heslop, H. E., A. C. M. Bianchi, F. T. Cordingley, M. Turner, C. P. De Mel, A. V. Hoffbrand, and M. K. Brenner. 1990. Effects of interferon $\alpha$ on autocrine growth factor loops in B lymphoproliferative disorders. J. Exp. Med. 172:1729-1734.

28. Janckila, A. J., C. Y. Li, K. W. Lam, and L. T. Yam. 1978. The cytochemistry of tartrate-resistant acid phosphatase. Am. J. Clin. Pathol. 70:45-55.

29. Stashenko, P., L. M. Nadler, R. Hardy, and S. F. Schlossman. 1980 Characterization of a human B lymphocyte specific antigen. J. Immunol 125:1678-1685.

30. Nadler, L. M., K. C. Anderson, G. Marti, M. P. Bates, E. K. Park, J. F. Daley, and S. F. Schlossman. 1983. B4, a human B lymphocyte associated antigen expressed on normal, mitogen activated, and malignant B lymphocytes. $J$. Immunol. 131:244-250.

31. Nadler, L. M., P. Stashenko, R. Hardy, A. van Agthoven, C. Terhorst, and S. F. Schlossman. 1981. Characterization of a human B cell specific antigen (B2) distinct from B1. J. Immunol. 126:1941-1947.

32. Fox, D. A., R. E. Hussey, K. A. Fitzgerald, A. Bensussan, J. F. Daley, S. F. Schlossman, and E. L. Reinherz. 1985. Activation of human thymocytes via the $50,000 \mathrm{kD}$ T11 sheep erythrocyte binding protein induces the expression of interleukin-2 receptors on both T3-positive and T3-negative populations. J. Immunol. 134:330-335.

33. Anderson, K. C., E. K. Park, M. P. Bates, R. C. F. Leonard, S. F. Schlossman, and L. M. Nadler. 1983. Antigens on human plasma cells identified by monoclonal antibody. J. Immunol. 130:1132-1138.

34. Reinherz, E. L., P. C. Kung, G. Goldstein, and S. F. Schlossman. 1979. Further characterization of the human inducer $\mathrm{T}$ cell subset defined by monoclonal antibody. J. Immunol. 123:2894-2896.

35. Reinherz, E. L., P. C. Kung, G. Goldstein, and S. F. Schlossman. 1980. A monoclonal antibody reactive with the human cytotoxic/suppressor $\mathrm{T}$ cell subset previously defined by a heteroantisera termed TH2. J. Immunol. 124:1301-1307.

36. Todd, R. F. III, L. M. Nadler, and S. F. Schlossman. 1981. Antigens on human monocytes identified by monoclonal antibodies. J. Immunol. 126:14351442. 
37. Hirata, Y., T. Taga, M. Hibi, N. Nakano, T. Hirano, and T. Kishimoto. 1989. Characterization of IL-6 receptor expression by monoclonal and polyclonal antibodies. J. Immunol. 143:2900-2906.

38. Miles, S. A., A. R. Rezai, J. F. Salazar-Gonzalez, M. Vander Meyden, R. H. Stevens, D. M. Logan, R. T. Mitsuyasu, T. Taga, T. Hirano, T. Kishimoto, and O. Martinez-Maza. 1990. AIDS Kaposi sarcoma-derived cells produce and respond to interleukin 6. Proc. Natl. Acad. Sci. USA. 87:4068-4072.

39. Carson, D. A., D. B. Wasson, R. Taetle, and A. Yu. 1983. Specific toxicity of 2-chlorodeoxyadenosine toward resting and proliferating human lymphocytes. Blood. 62:737-743.

40. Chomczynski, P., and N. Sacchi. 1987. Single step method of RNA isolation by acid guanidinium thiocyanate-phenol-chloroform extraction. Annal. Biochem. 162:156-159.

41. Yamasaki, K., T. Taga, Y. Hirata, H. Yawata, Y. Kawanishi, B. Seed, T. Taniguchi, T. Hirano, and T. Kishimoto. 1988. Cloning and expression of the human interleukin-6 (BSF-2/IFNB 2) receptor. Science (Wash. DC). 241:825828.

42. Aarden, L., E. De Groot, O. Schaap, and P. Lansdorp. 1987. Production of hybridoma growth factor by human monocytes. Eur. J. Immunol. 17:1411-1417.

43. Lindemann, A., W. D. Ludwig, W. Oster, R. Mertelsmann, and F. Herrmann. 1989. High level secretion of tumor necrosis factor-alpha contributes to hematopoietic failure in hairy cell leukemia. Blood. 73:880-884

44. Foa, R., M. Massaia, S. Cardona, A. G. Tos, A. Bianchi, C. Attisano, A. Guarini, P. F. di Celle, and M. T. Fierro. 1990. Production of tumor necrosis factor- $\alpha$ by B-cell chronic lymphocytic leukemia cells: a possible regulatory role of TNF in the progression of the disease. Blood. 76:393-400.

45. Browder, T. M., J. S. Abrams, P. C. Wong, and A. W. Nienhuis. 1989. Mechanism of autocrine stimulation in hematopoietic cells producing interleukin-3 after retrovirus-mediated gene transfer. Mol. Cell. Biol. 9:204-213.

46. Bejcek, B. E., D. Y. Li, and T. F. Deuel. 1989. Transformation by v-sis occurs by an internal autoactivation mechanism. Science (Wash. DC). 245:14961499.

47. Lang, R. A., D. Metcalf, N. M. Gough, A. R. Dunn, and T. J. Gonda. 1985. Expression of a hemopoietic growth factor cDNA in a factor-dependent cell line results in autonomous growth and tumorigenicity. Cell. 43:531-542.

48. Dunbar, C. E., T. M. Browder, J. S. Abrams, and A. W. Nienhuis. 1989. $\mathrm{COOH}$-terminal -modified interleukin-3 is retained intracellularly and stimulates autocrine growth. Science (Wash. DC). 245:1493-1496.

49. Levy, Y., A. Tsapis, and J. C. Brouet. 1991. Interleukin-6 antisense oligonucleotides inhibit the growth of human myeloma cell lines. J. Clin. Invest. 88:696-699.

50. Brach, M. A., N. A. Cicco, D. Riedel, T. Hirano, T. Kishimoto, R. H. Mertelsmann, and F. Herrmann. 1990. Mechanisms of differential regulation of interleukin-6 mRNA accumulation by tumor necrosis factor alpha and lymphotoxin during monocytic differentiation. FEBS (Fed. Eur. Biochem. Soc.) Lett. 263:349-354.

51. Buck, C., W. Digel, W. Schoniger, W. Stefanic, A. Raghavachar, H. Heimpel, and F. Porzsolt. 1990. Tumor necrosis factor- $\alpha$, but not lymphotoxin, stimulates growth of tumor cells in hairy cell leukemia. Leukemia. 4:431-434.
52. Rieckmann, P., F. D'Alessandro, R. P. Nordan, A. S. Fauci, and J. H. Kehrl. 1991. IL-6 and tumor necrosis factor- $\alpha$; autocrine and paracrine cytokines involved in B cell function. J. Immunol. 146:3462-3468.

53. Bergamaschi, G., M. Cazzola, V. Rosti, C. Carlo-Stella, V. Santini, L. Ponshio, F. A. Peverali, G. D. Valle, P. R. Ferrini, and E. Ascari. 1991. Tumor necrosis factor $\alpha$ modulates the messenger RNA expression of hematopoietic growth factor genes in fresh blast cells from patients with acute myeloblastic leukemia. Leukemia. 5:886-891.

54. Cicco, N. A., A. Lindemann, J. Content, P. Vandenbussche, M. Lubbert, J. Gauss, R. Mertelsmann, and F. Herrmann. 1990. Indeucible production of interleukin- 6 by human polymorphonuclear neutrophils: role of granulocyte-macrophage colony-stimulating factor and tumor necrosis factor-alpha. Blood. 75:2049-2052.

55. Saven, A., and L. D. Piro. 1992. Treatment of hairy cell leukemia. Blood. 79:1111-1120.

56. Gamliel, H., B. H. Brownstein, D. Gurfel, S. Wu, M. C. Rosner, and H. M. Golomb. 1990. B-cell growth factor-induced and $\alpha$-interferon-inhibited proliferation of hairy cells coincides with modulation of cell surface antigens. Cancer Res. 50:4111-4120.

57. Genot, E., M. A. Valentine, L. Degos, F. Sigaux, and J. P. Kolb. 1991. Hyperphosphorylation of CD20 in hairy cells: alteration by low molecular weight B cell growth factor and IFN- $\alpha$. J. Immunol. 146:870-878.

58. Vedantham, S., H. Gamliel, and H. M. Golomb. 1992. Mechanism of interferon action in hairy cell leukemia: a model of effective cancer biotherapy. Cancer Res. 52:1056-1066.

59. Billard, C., F. Sigaux, and J. Wietzerbin. 1990. IFN- $\alpha$ in vivo enhances tumor necrosis factor receptor levels on hairy cells. J. Immunol. 145:1713-1718.

60. Billard, C., N. Romquin, and J. Wietzerbin. 1992. Interferon- $\alpha$ modulation of cytokine receptor expression in tumor cells from B-cell malignancies. Proc. Am. Assoc. Cancer Res. 33:336. (Abstr.).

61. Jansen, J. H., G. J. H. M. Wientjens, R. Willemze, and J. C. Kluin-Nelemans. 1992. Production of tumor necrosis factor- $\alpha$ by normal and malignant $B$ lymphocytes in response to interferon- $\alpha$, interferon- $\gamma$ and interleukin-4. Leukemia. 6:116-119.

62. Hirano, T. 1991. Interleukin 6 (IL-6) and its receptor: Their role in plasma cell neoplasms. Int. J. Cell. Cloning. 9:166-184.

63. Shimizu, H., K. Mitomo, T. Watanabe, S. Okamoto, and K. Yamamoto. 1990. Involvement of the interleukin-6 gene by inflammatory lymphokines. $\mathrm{Mol}$. Cell Biol. 10:561-568.

64. Ishiki, H., S. Akira, O. Tanabe, T. Nakajima, T. Shimamoto, T. Hirano, and T. Kishimoto. 1990. Constitutive and IL-1 inducible factors interact with the IL-1 responsive element in the IL-6 gene. Mol. Cell Biol. 10:2757-2764.

65. Libermann, T. A., and D. Baltimore. 1990. Activation of interleukin-6 gene expression through the NF- $\mathrm{kB}$ transcription factor. Mol. Cell Biol. 10:23272334.

66. Zhang, Y., J. X. Lin, and J. Vilcek. 1990. Interleukin-6 induction by tumor necrosis factor and interleukin- 1 in human fibroblasts involves activation of a nuclear binding to a $\kappa \mathrm{B}-$ like sequence. $\mathrm{Mol}$. Cell. Biol. 10:3818-3823. 